\title{
A Brief Analysis of the Reform of Selection Methods for Postgraduates
}

\author{
SUN Li-shuang, ZENG Jia-li \\ School of Transportation Engineering, Shenyang Jianzhu University \\ Shenyang, China, 110168
}

\begin{abstract}
For the past few years, with the rapid development of the comprehensive reform of postgraduate education, the aim of this study was to make the enrollment mechanism of postgraduates are more meet the demand of new situation. This paper has put forward some new advice, for example put Emotional Quotient into the selection system etc. which are based on the guidelines of the 13th Five-Year Plan in education, a lot of investigation and analysis, discussed with the educational scholars in depth, which have been done by the author, and a certain scale of practices in universities. Our results show that pushing classified examinations, optimizing examination subjects and contents in the first stage, strengthening the re-examination, focusing on the importance of ability, paying more attention to performance evaluation, establishing a more scientific and effective examination and selection system, which must be enforced.
\end{abstract}

Keywords-Postgraduate selection methods; Classified examination; Re-examination; Reform

\section{INTRODUCTION}

In recent years, education reform has become a hot issue among the department in charge of education, colleges and even the whole society. In 2010, 'Outline of national medium and long-term planning framework for education reform and development (2010 - 2020)' was issued [1], and clear demands for deepening the comprehensive reform of education were proposed on the 18th Central Committee of the CPC, which made the graduate enrollment and selection system received much concern. In 2013, the 'Opinions on deepening the reform of Graduate Education' (education research [2013] 1) was issued by the ministry of education, the national development and the reform commission and the ministry of finance, which proposed to vigorously promote the reform of graduate enrollment system and establish a scientific and fair graduate enrollment and selection method. In September 2013, 'Notice on the further strengthening of recommending outstanding undergraduate graduates exemption for postgraduate' (education department [2013] 8) was issued by the general office of the ministry of education which was the first to strengthen the exchange for the Postgraduates Candidates Exempt from Admission Exam, and who can register examinations for all of other organizations. According to the 13th Five-year Plan for the national economy and social development, in order to meet the need of high-level talent required by the economy and social development in the new period and to comprehensively improve the graduate education

The 2016 Postgraduate Education Innovation Project of Shenyang Jianzhu University (2016-ZD-23). quality, the reform of the degree and graduate education will be further promoted. Nevertheless, any reform has a long period, how to fundamentally set the accurate goal for the graduate enrollment and selection system and base on the goal to make an enrollment and selection system which was adaptive to the social development and helpful to the prosperous development of graduate education has been a problem the education governors sustainably thinking about.

\section{THE EXISTING PROBLEMS IN THE ENTRANCE EXAMINATION AND ENROLLMENT TO GRADUATE LEVEL EDUCATION NOW}

Since1951, the reform in the entrance examination and enrollment to graduate level education has been continuing, which has carried out several times so far, and has averaged about 1.5 years once [2]. Such a high frequency of reform not only has illustrated the importance of examination and enrollment system, but also has showed that it is a social problem to solve difficultly. The problems of examination and enrollment system have not been solved by the frequent reform, which was even criticized many times in an open environment. Since the criticisms have been founded on every aspect, the focus of criticisms is inconsistent, or even contrary to. It is mainly focused on the following aspects:

\section{A. Professional Course Test}

(1) Course tests are not standardized. The first stage of the entrance examination to graduate level education exists problems, such as the randomness and large variety of the tests development by admission unit, marking in different ways etc. so that some universities reduced the difficulty of tests in order to complete the post-graduate enrollment plan, which has affected the quality of the test development by admission unit.

(2) Test results of course tests are not comparable, but the enrollment system is national uniformed. As long as there is a subject mark cannot reach the standard, then the other subjects are not meaningful, "cut-off"[3] is obvious.

\section{B. Re-examination}

(1) Re-examination mode is simple, which is simply applied to the model of academic postgraduates at present [4], and the simple calculation methods are used for summing up the second stage examination mark, which are great limitations in the selection. 
(2) There is a big constraint in the existing re-examination for candidates' creative and practical ability what focuses on knowledge rather than ability, single exam forms, the lack of scientific appraisal and other issues. In recent years, there is a phenomenon that some specialties' of lacking students [5], for example, Shenyang Jianzhou University is shortage of students in engineering, which has an impact on the university dominance. So the candidates will firstly consider adjusting to a less competitive school or specialties. To finish institute's enrollment policy, tutors hope that through future research education to develop those who lack professionalism.

(3) Ministry of Education provides that the university can decide to take a certain percentage of the students who do not reach to the standard. There are different ways to make sure that they become the candidates for the re-examination. Both transparency and openness are not enough,

(4) The first stage examination mark determine the graduate enrollment completely, it has ignored the tutor' s autonomy, and limited the autonomy of the tutor to enroll students according to their knowledge and ability.

\section{The System of Recommendation with Exam-exemption}

(1) The selection system is not perfect, and a lack of measurement standards, which have resulted the level of postgraduate candidates exempt from admission exam are different.

(2) Most of them are recommended to continue to study at the original university and lack of academic exchanges between colleges.

\section{Moral Education}

Now, thinking highly of professional knowledge, not much for the quality appraisal. The university will take the questionnaire to the unit or college through the "political careful" to understand the candidates in the political and moral situation. In order to increase promotion rate of graduates, whose college will inform the good news. So the enrollment unit can not accurately obtain the real situation of candidates.

\section{E. Supervision Mechanism}

In the re-examination of post-graduates, the role of the supervision mechanism can be mainly reflected in the examination standards, exam procedure, opening test achievement, review and so on. However, in the operation, due to time is pressing and the task heavy, it is difficult to play an effective supervision mechanism, which also led to reexamination works are in trouble.

\section{FOR SOME SOLUTIONS TO THE ABOVE PROBLEMS}

\section{A. The reform measures for the recommendation with Exam- exemption selection system}

1) Establishing a scientific postgraduate push and reception system

In the stage of determining the exemption, firstly, the evaluation index of graduate evaluation system should be determined. In accordance with the "13th Five-Year Plan" of national education, we will adhere to the concept of "innovation, coordination, green, open and shared", to ensure that the works are scientific and practical, the leaders and the teachers of the Shenyang Jianzhu University, who are through continuing to research, analyze and summarize, putting forward the five indicators of comprehensive quality evaluation system of college students. As follows: learning performance, ideological and psychological education, scientific research potential and teamwork Ability, second language level, computer level. Combining with the weight of above indicator, and the Ministry of Education on the number of the recommendation with Exam-exemption, and determine the list ultimately.

Secondly, in the acceptance of the recommendation with Exam-exemption, the university should be based on professional degrees and academic degrees to develop different disciplines of postgraduates, and the establishment of information services to ensure that the work is fairer, more reasonable, scientific and efficient implementation. In the "13th Five-Year Plan", it is estimated that by 2020, the total number of graduate students will reach 2.9 million. Professional postgraduates will account for about $60 \%$. When the professional level of candidates are enrolled by university, which should exam the practice ability, to better meet the scientific and technological innovation and talent market demand. For example, Wu Han University, Tong Ji University has hold summer camp to admission the students with operating ability, the practical ability, thus selected excellent students.

2) The establishment of inter-disciplinary and multi-batch selection system

According to the "13th Five-Year Plan", the Ministry of Education put forward the policy and requirements that university should establish the open and cooperation mode and individual education plans (IEPs) to fully stimulate the enthusiasm of postgraduates to practice and innovation. Combined with the characteristics of Shenyang Jianzhu University and years of experience in graduate enrollment, we actively have explored the reform mechanism of the recommendation with exam-exemption selection with the "inter-disciplinary exchanges, batch re-examination", and constantly improve the selection system of the recommendation with exam-exemption students.

With the rapid development of national strategy and economic society, majors development are also different, there are more students and fierce competition for some popular majors. When students fill in the volunteer, they can also fill three different related professions in the school, according to graduate student register population and the number of the recommendation with Exam-exemption students, the postgraduate candidates will be divided into three batches of re-test, which is in turn and at different times[4]. Those who are admitted by a previous batch may not participate in the latter batch. But correspondingly, who can continue to take another re-examination. Each major has determined the enrollment list, according to the number of their recommendation with Exam-exemption candidates, reexamination achievement and comprehensive quality. 


\section{B. Reform Measures for the Professional Subjects and Content of the Entrance Examination}

The major examinations of academic and professional postgraduate should be apart [6]. Postgraduate is divided into academic and professional postgraduate in China. Academic master education is based on the cultivation of teaching and researching. Professional master's degree is a professional background, aimed at cultivating a solid theoretical basis, and talent training of the comprehensive and applied type [5]. Professional degree and academic degree in the training have their objectives, so the teaching methods and content, grant degree standards and requirements are different, as well the examination. Examination content can be composed of two parts: occupation test and specialty test [6]. The occupation test does not involve the specific content. The purpose is to measure research potential. Specialty test is mainly to assess the basic knowledge of candidates and the ability to solve practical problems. In order to achieve the classification selection system, specialty test should be based on different types of graduate students, targeted to study, rather than according to reducing the difficulty of the knowledge points that are used in examining of the academic graduate students to achieve.

\section{Reform of the Re-examination System}

(1) Establish a rigorous re-examination organization, and develop standardized re-examination procedures to ensure that Postgraduate enrollment is open, fair and just.

(2) The establishment of re-examination assessment evaluation indicators and scoring rules. The one is reexamination written test, another is GPA in college. The written test of the candidates is focuses on assessing the basis of the theory, logical thinking, written expression, ability expending. The GPA in college can from the accumulation of knowledge, for the research of students have a certain prediction. According to different majors, as well as the number of enrollment to determine the weight between the two, as a new indicator of the evaluation of candidates.

(3) The establishment of comprehensive quality evaluation indicators and scoring rules. Under the premise of the 13th Five-Year Plan in education, get through a large number of research and in the exchange of those who have engaged in long-term Postgraduate teaching, the author has gotten some inspiration: Determine the quality of graduate students is not just the mark, but the comprehensive quality. Combined with the Shenyang Jianzhu University Postgraduate enrollment situation, summed up the five indicators to evaluate the comprehensive quality of candidates. Followed by: knowledge and innovation, teamwork and organizational ability, the second language level, computer operating ability, ideological and moral education. The re-examination units shall assess the comprehensive quality of the candidates by the personal data provided by self and scoring them according to quantify the weight of achievement indicator.

(4) The establishment of re-examination interview evaluation indicators and scoring rules [7]." demands for service, improve the quality " has become a new direction to the reform of Postgraduate, combined with the development of
Chinese characteristics Postgraduate education and rendered with nearly 5,000 years of traditional culture, Emotional Quotient is an indicator gradually to measure the basic quality of Postgraduate. The author through reading a large number of literature and referring to the results of predecessors during the reform process of Postgraduate selection system, who found that the results: EQ is not prominent, but in order to cultivate Postgraduate who are comprehensive development in moral, double intelligence, spots, aesthetics and labor education, so it would have to consider that add the EQ in the examination. In order to respond to 13th Five-Year Plan in education, Shenyang Jianzhu University put forward four considerations in the interview. As follows: professional practice ability, etiquette cultivation, adaptability, language (the mother language and the second language) expressive ability. According to the scoring rules for scoring, and multiply corresponding ratio which is used to measure the interview results for the candidates.

(5) In the implementation of the entire process of reexamination, the postgraduate tutor should have a certain right to decide who is the most suitable students to keep studying by directly doing a thorough study of candidates, thereby letting the instructor give play to the role of mentor fully.

\section{Supervision Mechanism Reforms}

(1) Setting questions under supervision. In case of the release of the papers, the staff in the Graduate Admissions Office should set progressive relationship between the teachers who make the paper before signing confidentiality agreements level by level. In addition, the directors of individual departments make arrangements about the teachers who analyze and group the questions and clear responsibility commitment and implement accountability system.

(2) Printing under supervision, at the same time the Graduate Admissions Office is in charge of print, the staff among the all subjects binds the paper interjectionally.

(3) The written test evaluation under supervision, carry out training for evaluation personnel in order to emphasize discipline, clear disciplinary responsibility and strictly abide by the rules of evaluation.

(4) On-site inspection under supervision, the school should supervise the interview site and record by video to improve interview objectivity, openness and standardization.

(5) Admission under supervision, open admission procedures and compare candidates' notes as well as educational background to ensure that admission is accurate.

\section{E. Admission reforms}

Promoting information disclosure, publicity admission process improves transparency. In 2013, the administration departments implemented the "The Five Steps System of Government affairs public" aimed at improving the quality of work. In this guide, apply it to the graduate student selection system, allowing candidates to maximize the grasp of information of each link, and avoiding the asymmetric information caused by misunderstanding and disputes. It is not 
only to achieve the mutual supervision, but also reach to strengthen information disclosure and social supervision", this is the purpose of "The 13th Five-Year Planning ". The author defines it as "graduate selection information disclosure five steps. The five steps are: opening all the candidates entrance grades; ranking public entrance grades; public re-examination rules, procedures, test goals, scoring rules, score calculation method; opening re-examination results; enrollment results.

\section{CONCLUSION}

Under the premise of studying the 13th Five-Year Education Plan carefully ,the author has sorted out a variety of questions combining with the characteristics of Shenyang Jianzhu University and the nature of it, the problems of enrollment and the reception process to Postgraduate Candidates Exempt from Admission Exam and the entrance examination, re-examination are sort out. For these problems, through survey and constantly explore, the author summed up some effective solution. Shenyang Jianzhu University through the reform of graduate student selection system, not only greatly improve the quality of graduate students but also play a guiding role on the teaching of undergraduate students. Develop and perfect the graduate student enrollment selection system which is aim at adapting to the high-level talent needs in the new era of economic and social development, thus comprehensively improve the quality of post- graduate education, and cultivate more high-quality talents, with a sense of mission and social responsibility, innovative spirit [9] and practice Ability.

\section{REFERENCES}

[1] LIU Hang. Reflections on Reforming of the graduate admissions Selection System In Chinese [J]. Journal of Jilin Jianzhu University, 2015, (4).

[2] HU Da-hui. Graduate admissions quantitative analysis and recruitment selection system reform-take Zhejiang university graduate admissions analysis as an example In Chinese [J]. Higher Education Forum, 2014, (9).

[3] LIU Lei. Research on the Problems and Reform Countermeasures of Postgraduate Enrollment System In Chinese [J]. Industrial \&Science Tribune,2011, (10).

[4] CHEN Rui. An analysis of the reform in the entrance examination and enrollment to graduate level education In Chinese [J]. Theory and Practice of Education ,2012, (10).

[5] LIU Yi-bo. The admissions re -examination reform research on full time graduate candidates In Chinese [J]. Journal of Qiqihar University (Phi\& Soc Sci),2015,(2).

[6] ZHENG Yan, DUAN Ya-min. research of evaluation system of the fulltime professional degree Master ' $\mathrm{s}$ admission re-examination In Chinese [J]. Journal of Shijiazhuang University of Economics, 2015, (6).

[7] GAO Ming-guo. A Probe into the Mode of Enrollment Examination for Master Graduates in China In Chinese [J]. Journal of Higher Education, 2016, (18).

[8] WANG Hui-jun,SHEN Ya-jun .An Analysis of the Current Situation of Enrollment of Postgraduates from Academic Degree and Professional Degree In Chinese [J].Management Observer, 2016, (1).

[9] BAI Rong, MIAO Guo-hou. The principles and contents of graduate evaluation index system of selection and re-examination creative talents --implement based on "long-term talent development program" In Chinese [J].Higher Education,2011,(12).

[10] LIU Shao-hua. Analysis on the Reform of Graduate Students' Admission System in the New Situation In Chinese [J]. Journal of Educational institute of Jilin province, 2015, (52). 